\title{
O trabalho precário nos Institutos Federais: uma análise dos processos de intensificação do trabalho verticalizado
}

\author{
José Júlio César do Nascimento Araújo1 \\ ORCID: 0000-0003-1045-3284 \\ Arminda Rachel Botelho Mourão \\ ORCID: 0000-0002-1940-9477
}

\section{Resumo}

0 artigo faz uma revisão do conceito de precarização do trabalho. 0 método de exposição e análise segue a abordagem do materialismo histórico dialético. A escolha das fontes seguiu a pesquisa bibliográfica e de campo, com amparo da análise de conteúdo temáticocategorial. Apontam-se alguns elementos precarizantes do trabalho docente nos Institutos Federais (IFs), como o fetiche da nova carreira nos IFs, a verticalização e a intensificação do trabalho. Discute-se que há na instituição uma polivalência exigida pela verticalização do trabalho. Essa intensificação precariza o trabalho docente à medida que exige do professor maior esforço mental; conhecimento de processos diversos; adaptabilidade de sua prática à diversidade de turmas em que atua; trabalho emotivo diversificado; intensificação de sua lógica de atuação, de atenção e de controle; maior tempo de preparação das aulas e de conteúdos para abordar em sala de aula. Assim, a porosidade de trabalho, o tempo de reflexão e o tempo de não-trabalho são engolidos pelas atribuições de preparação do trabalho. Por fim, aponta as dimensões da práxis que a categoria precarização deve apresentar no campo da interpretação e luta do/pelo trabalho docente. 0 texto conclui que as mediações entre teoria e práxis devem compreender a precarização como termo político, um processo caleidoscópico para apreender a exploração constante do novo quantum do trabalho, sem a alteração de seu estatuto, além dos reflexos subjetivos de sofrimento, do adoecimento provocado pelas transformações constantes, impostas à organização do trabalho. Dessa forma, nos IFs, o processo de verticalização do trabalho torna a ação docente precarizada.

\section{Palavras-chave}

Institutos Federais - Precariedade - Polivalência - Verticalização.

1- Instituto Federal do Acre, Rio Branco - AC, Brasil. Contato: jose.araujo@ifac.edu.br

2- Universidade Federal do Amazonas, Manaus - AM, Brasil. Contato: arachel@uol.com.br

https://doi.org/10.1590/S1678-4634202147226325

This content is licensed under a Creative Commons attribution-type BY-NC. 


\section{Precarious work in Federal Institutes: an analysis of the processes of intensification of verticalized work}

This article makes a review of the concept of precarious work. Our method of exposure and analysis follows the approach of dialectical historical materialism. Our choice of sources followed the bibliographic and field research, with the help of thematic-category content analysis. Some precarious elements of the teaching work in Federal Institutes (IFs) have been pointed out, such as the fetish of the new career in the IFs, the verticalization and the intensification of teachers' work. It is discussed here that there is in the institution a polyvalence required by the verticalization of the work. This intensification makes the teaching work more precarious since it requires greater mental effort from the teacher, his/ her knowledge of various processes; his/her adaptability of its practice to the diversity of classes in which it operates; diverse emotional work; intensification of its logic of action, of attention and control; longer preparation time of classes and contents covered in the classroom. Thus, the porosity of work, the time needed for reflection and the time of nonwork are swallowed by the tasks of preparation of the work. Finally, the article points out the dimensions of praxis that the precariousness category must present in the field of interpretation and struggle of/for teaching work. Our conclusion is that the mediations between theory and praxis must regard precariousness as a political term, a kaleidoscopic process which aims to apprehend the constant exploration of the new quantum of work, without changing its status, in addition to the subjective reflections of suffering, the teachers' illnesses caused by constant transformations imposed on the organization of work. Thus, in the IFs, the process of verticalization of work makes the teaching practice precarious.

\section{Keywords}

Federal Institutes - Precariousness - Multipurpose - Verticalization.

\section{Introdução}

0 presente artigo faz uma revisão do conceito de precarização, assumido como categoria de análise às abordagens teóricas críticas. 0 olhar centra-se na precarização do trabalho docente e da formação nos Institutos Federais (IFs), sob o prisma do mundo do trabalho.

A pesquisa de campo e bibliográfica apontou cinco elementos desse processo de precarização do trabalho nos IFs, após sua institucionalização em 2008. Destacam-se: 1) o fetiche da nova carreira nos IFs; 2) a verticalização; 3) a intensificação do trabalho; 4) o aumento da densidade laboral; e 5) as mudanças na carga horária docente.

Este trabalho conclui que a reestruturação da Rede de Escolas Técnicas Federais no Brasil, em 2008, construiu um novo formato de trabalho que associado à hibridização institucional (oferta de vários níveis de ensino em única instituição); à fragmentação da 
carreira do professor de Educação Básica Técnica e Tecnológica (EBTT); à verticalização como uma prática administrativo-gerencial leva a uma intensificação do trabalho docente.

$\mathrm{Na}$ análise, apontamos como a categoria precarização tem sido apresentada em algumas análises de pesquisadores de visão crítica e de orientação marxista, para, na sequência textual, discutir o fetiche da nova carreira nos IFs, a verticalização e a intensificação do trabalho nesses espaços.

0 artigo está dividido em quatro seções. A primeira, descreve a metodologia usada; na segunda, apresentam-se as abordagens teóricas apontadas para a categoria precarização; na terceira, discutimos o trabalho docente nos IFs e seus elementos precarizantes; e, por fim, nas conclusões, apontam-se seis questões que devem ser levadas em conta na luta e na pesquisa sobre trabalho docente.

\section{Metodologia}

A partir de ampla leitura acerca da educação profissional e a transformação na Rede de Educação Profissional e Tecnológica, o Materialismo Histórico Dialético e a práxis como docente em IF possibilitaram-nos: as reflexões e a categorização sobre a realidade enfrentada - com a finalidade de construir o real por meio da teoria - e reconstruir a teoria através da práxis. Nessa fase, de pesquisa bibliográfica e documental, buscou-se uma discussão contextualizada e histórica da problemática da precarização, para assim:

[...] fundamentar teoricamente o objeto de estudo, contribuindo com elementos que subsidiam a análise futura dos dados obtidos, [...] [imprimindo] sobre eles a teoria, [e] a compreensão crítica do significado neles existentes." (LIMA; MIOTO, 2007, p. 44).

A seleção dos textos foi realizada nos repositórios das revistas, tendo como filtros $<$ precarização 0 , <precarização do trabalho $>$ e < Institutos Federais $>$. Além disso, foram consultados livros de autores que estudam a temática no mundo do trabalho.

Após essa fase, os documentos, assim como a literatura, foram organizados e analisados utilizando o software para análise de pesquisa qualitativa $N$ Vivo 11 Starter e os pressupostos da Análise de Conteúdo temático-categorial (GUERRA, 2014). Como apresentamos a seguir:

I - Organização da análise:

- Leitura flutuante e analítica;

- Definição das unidades de análise com base nas questões norteadoras da pesquisa;

- Identificação das categorias e subcategorias emergentes.

II- Exploração do material:

- Construção das categorias para análise;

- Codificação e categorização dos dados com apoio de software para análise de pesquisa qualitativa $N$ Vivo 11 Starter for Windows. 


\section{III- Análise dos resultados:}

- Organização dos quadros de análise com os extratos de discurso correspondentes as categorias;

- Análise do conteúdo;

- Inferências e interpretações.

A pesquisa de campo consistiu na aplicação de 30 questionários (com 25 questões abertas e fechadas) para os discentes das turmas de Licenciatura em Matemática dos anos 2014, 2015, 2016, tendo dez entrevistados em cada turma. Com os docentes que trabalham/ trabalharam na referida licenciatura foi aplicado um questionário com 25 questões de múltipla escolha. Neste artigo, apresentam-se os dados coletados nos dois blocos que versavam sobre o trabalho e a formação no IF pesquisado. 0 lócus de pesquisa foi um Instituto Federal da Amazônia Ocidental que oferta licenciatura em Matemática desde 2011.

Os dados bibliográficos e coletados por meio da pesquisa de campo foram organizados seguindo os pressupostos da Análise de Conteúdo Categorial e codificados com apoio do software NVivo 11 Starter. A intepretação foi ancorada na teoria marxista, entendendo que a investigação deve se apoderar da matéria, em seus pormenores, acompanhada das diferentes formas de desenvolvimento de dado problema e suas mediações com a realidade em uma perspectiva histórica (MARX, 2014).

\section{A precarização como categoria de análise do trabalho humano}

A categoria precarização do trabalho tem sido discutida a partir da classificação das problemáticas advindas das transformações espectrais do mundo do trabalho. Porém, em algumas outras abordagens, a precarização social do trabalho dá-se pela vulnerabilidade das formas de inserção e desigualdades sociais; pela intensificação do trabalho e terceirização; pela insegurança e prejuízos à saúde no trabalho e do trabalhador; na perda da identidade individual e coletiva; pela fragilização da organização dos trabalhadores e pelo descarte do direito do trabalho (DRUCK, 2011). Também se classificam como precarização as atuais mudanças no mundo do trabalho que ampliam o desemprego, destroem os salários, as condições de trabalho e leva a processos de terceirização dos serviços (NOZAKI, 2004).

A precarização ocorre não somente no sentido do uso da força de trabalho como mercadoria; mas também na "precarização do homem que trabalha", no sentido de desefetivação do homem como ser genérico (ALVES, 2010). Porém, é possível visualizar uma abordagem relacional e construtivista da precariedade do trabalho, identificando a maneira como esse se inscreve no mundo e nas relações sociais. Por outro lado, o trabalho como um conjunto de atividades realizadas tanto em condições objetivas particulares e condições subjetivas (VARGAS, 2016).

Bosi (2007), analisando precarização no contexto do trabalho docente, aponta que, do ponto de vista do capital, se trata de aumentar o trabalho docente em extensão e intensidade. Antunes e Praun (2015, p. 423) destacam que a intensidade é fruto da lógica destrutiva do capital que explora sem limites a força de trabalho, ainda que não possa 
prescindir do trabalho vivo para sua reprodução. Além disso, como destaca VizzaccaroAmaral (2011), o trabalho também é precarizado por meio da aplicação das inovações técnico-gerenciais que se propõem a mediar uma relação entre Capital e Trabalho por meio de uma suposta antecipação dos conflitos.

Mota (2011) indica que no Brasil há um alargamento de competências para o trabalho que coincidem com as novas formas de precarização no governo de Fernando Henrique Cardoso. Na dimensão jurídico-administrativa, observa-se uma expressiva produção legislativa para precarizar o trabalho através da jornada parcial, o banco de horas, o contrato a prazo determinado, as comissões de conciliação prévia e a intensificação das hipóteses legais autorizadoras da terceirização. Para o autor, a precarização mostra-se nas diversas formas de flexibilizar o trabalho e de torná-lo inseguro ao trabalhador.

Assim, como classificam Cerón e Corte Cruz (2012), a precarização do trabalho insere-se na dinâmica da recente reestruturação capitalista - fenômeno que é resultado do avanço do modelo de acumulação, traduzido na permanente luta por competitividade, eficiência e lucro, provocando flexibilidade laboral, novas formas de contratação, menores salários, perda de direitos trabalhistas e ataque às organizações sindicais. Em síntese, o trabalho precário mostra-se perceptível em dois níveis: precarização social do trabalho e precarização social do trabalhador, como podemos visualizar na figura abaixo:

Figura 1 - Trabalho precário - processos 3

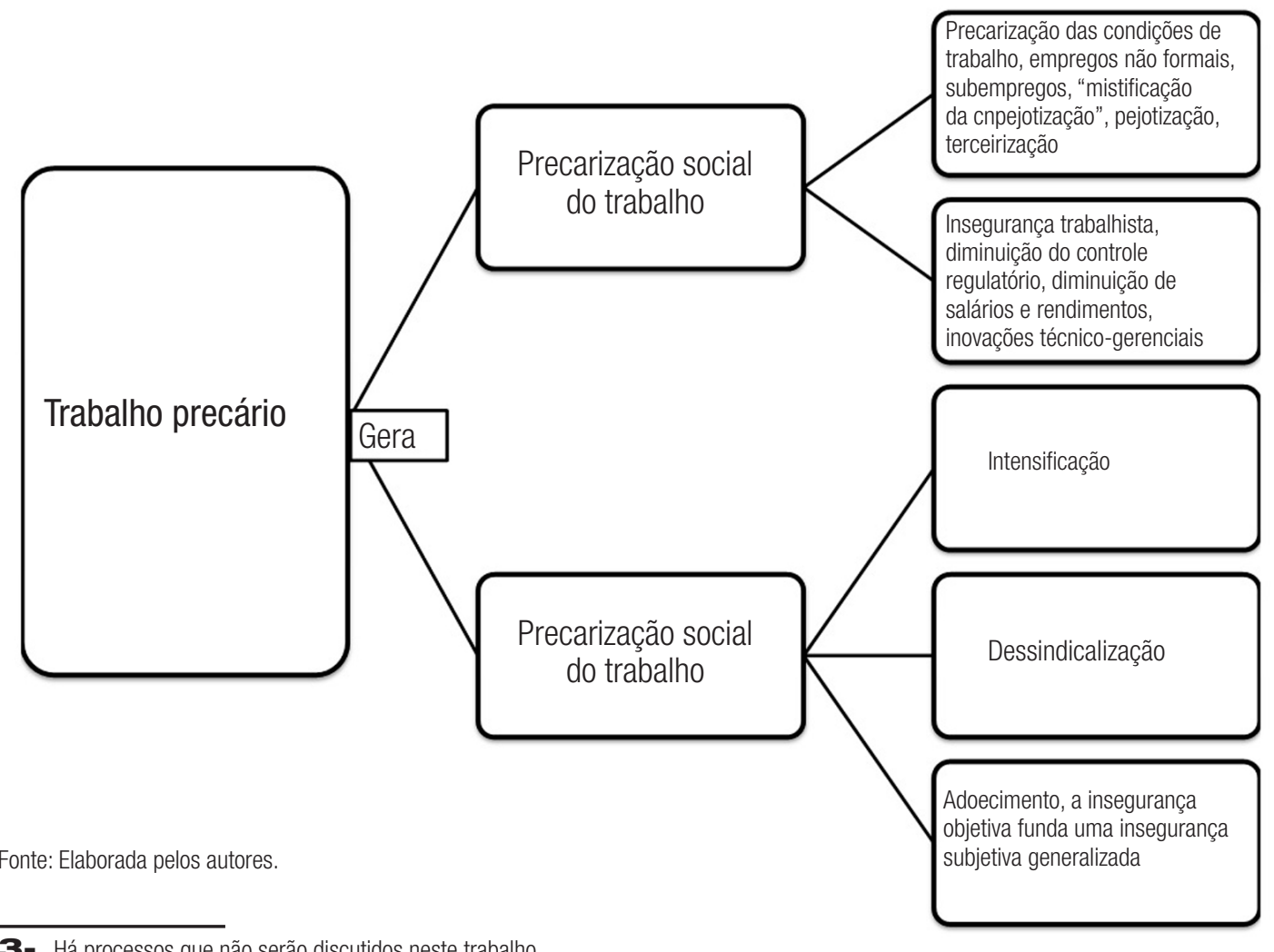

3- Há processos que não serão discutidos neste trabalho. 
Nesse sentido, a precarização traduz-se também como um processo de intensificação do trabalho, que se configura como a diminuição dos tempos mortos ${ }^{4}$ (MARX, 2014), de tal forma que o trabalho se torne cada vez mais denso, diminuindo sua porosidade, seja entre os tempos intervalares, seja entre carga de trabalho que o docente precisa enfrentar para satisfazer suas necessidades básicas. Marx compreendia o trabalho como processo do qual participam o homem e a natureza, de modo que o ser humano, com sua ação, impulsiona, regula e controla seu intercâmbio material com a natureza, "atuando assim sobre a natureza externa e modificando-a e, ao mesmo tempo, modifica sua própria natureza" (MARX, 2014, p. 211).

0 trabalho é a categoria ontológica da humanização. É o trabalho que possibilita a hominização e a humanização ao mesmo tempo em que gera sofrimento e alienação, pois ao modificar a natureza, o ser se vê modificado ou estranhado pelo que criou. 0 homem "não transforma apenas o material sobre o qual opera; ele imprime ao material o projeto que tinha conscientemente em mira” (MARX, 2014, p. 212).

Marx (2014, p. 409) compreende intensificação do trabalho por meio de cinco metáforas que se autocompletam para explicar o fenômeno da intensidade laboral: gasto aumentado de trabalho em um mesmo espaço de tempo, elevada tensão da força de trabalho, preenchimento dos intervalos dos dias de trabalho, condensação e densidade laboral. Partindo desse pressuposto, Dal Rosso (2008) compreende que há intensidade quando se verifica maior gasto de energias do trabalhador no exercício de suas atividades cotidianas.

Com base em Dal Rosso (2008), pode-se afirmar que o trabalho intensificado precariza a qualidade dos processos e dos objetos, pois a intensificação se traduz como:

[...] processos de quaisquer natureza que resultam em um maior dispêndio das capacidades físicas, cognitivas e emotivas do trabalhador com o objetivo de elevar quantitativamente ou melhorar qualitativamente os resultados. (DAL ROSSO, 2008, p. 23).

Assim, a intensificação constitui uma dimensão social da exploração do trabalhador e da precarização do trabalho. Esse conceito está ligado ao aumento do labor, mas não somente a isso, pois ela se constitui, também, numa "dimensão social particular da exploração, distinta da força produtiva (produtividade) e do prolongamento da jornada de trabalho" (PINA; STOTZ, 2014, p. 153). Na literatura, notam-se alguns paradigmas que descrevem a precarização do trabalho, tais como:

a) Incorporação de um maior quantum de trabalho pelo aumento da grandeza extensiva da jornada de trabalho expresso no aumento do produto valor global - prolongamento da jornada de trabalho, extração e ampliação da mais-valia (PINA; STOTZ, 2014).

b) A intensificação da exploração da força de trabalho - flexibilidade, polivalência e policompetência como fundamentos da organização talylorista - fordista de produção (SANTOS, 2011).

4- É o tempo livre que permite ao homem a criação (MARX, 2014). Sem tempo para reflexão sobre o seu trabalho ou sobre as formas de aprimorá-I0, 0 trabalho torna-se estranhado e alienado, pois o trabalhador já não domina todos os meios necessários à sua produção. Assim, já não reconhece o trabalho realizado nem o produto da realização do seu trabalho (MARX, 2014). 
c) A intensidade como noção geral aplicável a todas as relações de trabalho e não apenas ao sistema assalariado (DAL ROSSO; CARDOSO, 2015).

e) Entre professores, o processo de intensificação do trabalho evidencia sujeitos sobrecarregados e insatisfeitos, sobretudo, pelo excesso de responsabilidade e perda da especificidade da tarefa de ensinar (LOURENCETTI, 2004).

f) A intensificação tem gerado emoções bastante negativas e geradoras de frustrações entre professores como a irritação, a angústia, o sofrimento, o adoecimento, e a desmotivação (MOURA, 2013).

Nesse sentido, aproximando esta análise de seu objeto, no mundo do trabalho educativo um dos principais efeitos da flexibilidade imposta pelos processos de reforma educativa é a precarização. Provocada, em parte, pelas mudanças nas relações de trabalho que são criadas no interior das escolas e nas formas de contratação dos sistemas de ensino. São comuns: regimes de trabalho temporário; carga horária que precisa ser complementada em mais de um turno; condições de trabalho insalubres; pressão das avaliações internas e externas; informatização da rotina de trabalho; escolas sem material e salas superlotadas que têm caracterizado a precarização social do trabalho docente ${ }^{5}$.

Por outro lado, as reformas educativas têm perturbado a vida profissional dos professores, principalmente, em três áreas: em primeiro lugar, as alterações curriculares que resultaram em propostas decorrentes de conceitos de mercado impostos à educação; em segundo lugar, na modificação das relações entre as escolas, alunos, pais e sociedade em geral; e, por fim, na degradação da profissão de professor que, a cada dia, tem se mostrado mais precária e fragmentada (CERÓN; CORTE CRUZ, 2012).

Portanto, a precarização no mundo da escola não pode ser entendida apenas como o trabalho executado em condições inadequadas que gerem sofrimento e/ou adoecimento do trabalhador. Para além desse aspecto, no âmbito do trabalho do professor, a precarização consolida-se como processos dinâmicos e complexos de exploração da força de trabalho, programas arrojados de intensificação do trabalho docente que geram sofrimento psíquico provocado pelas cobranças e imposições dos sistemas de ensino, das avaliações de larga escala e, por fim, pelo alargamento das competências que são exigidas do professor para executar o seu trabalho.

\section{A precarização do trabalho e a realidade do trabalho nos Institutos Federais}

0 trabalho docente nos Institutos Federais, em muitas de suas dimensões, comporta processos de precarização envoltos em mecanismos de intensificação, diversificação, polivalência, versatilidade, flexibilidade que exigem desse trabalhador policompetências para executar o seu trabalho. Amiúde:

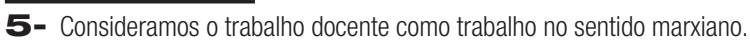


[...] a introdução de práticas polivalentes que representam o acúmulo de tarefas, seja sob o ponto de vista quantitativo, seja sob o ponto de vista qualitativo, e de práticas versáteis e flexíveis implicam maior adensamento do trabalho real. (DAL ROSSO, 2008, p. 155).

A precarização do trabalho nos IFs é o resultado das profundas transformações societárias no mundo do trabalho e dos ajustes neoliberais que fundamentam as políticas educacionais na atualidade. Por isso, a análise desse fenômeno não pode prescindir da intensa reflexão acerca da crise do sistema capitalista e das formas de organização da produção e da classe trabalhadora, e/ou sobre a desestabilização dessa organização da classe trabalhadora nos diversos espaços sócio-ocupacionais e políticos.

Como sintetizamos na figura 2, diversos processos constroem a precariedade da atuação docente nos IF:

Figura 2 - Processos de precarização do trabalho docente nos IFs

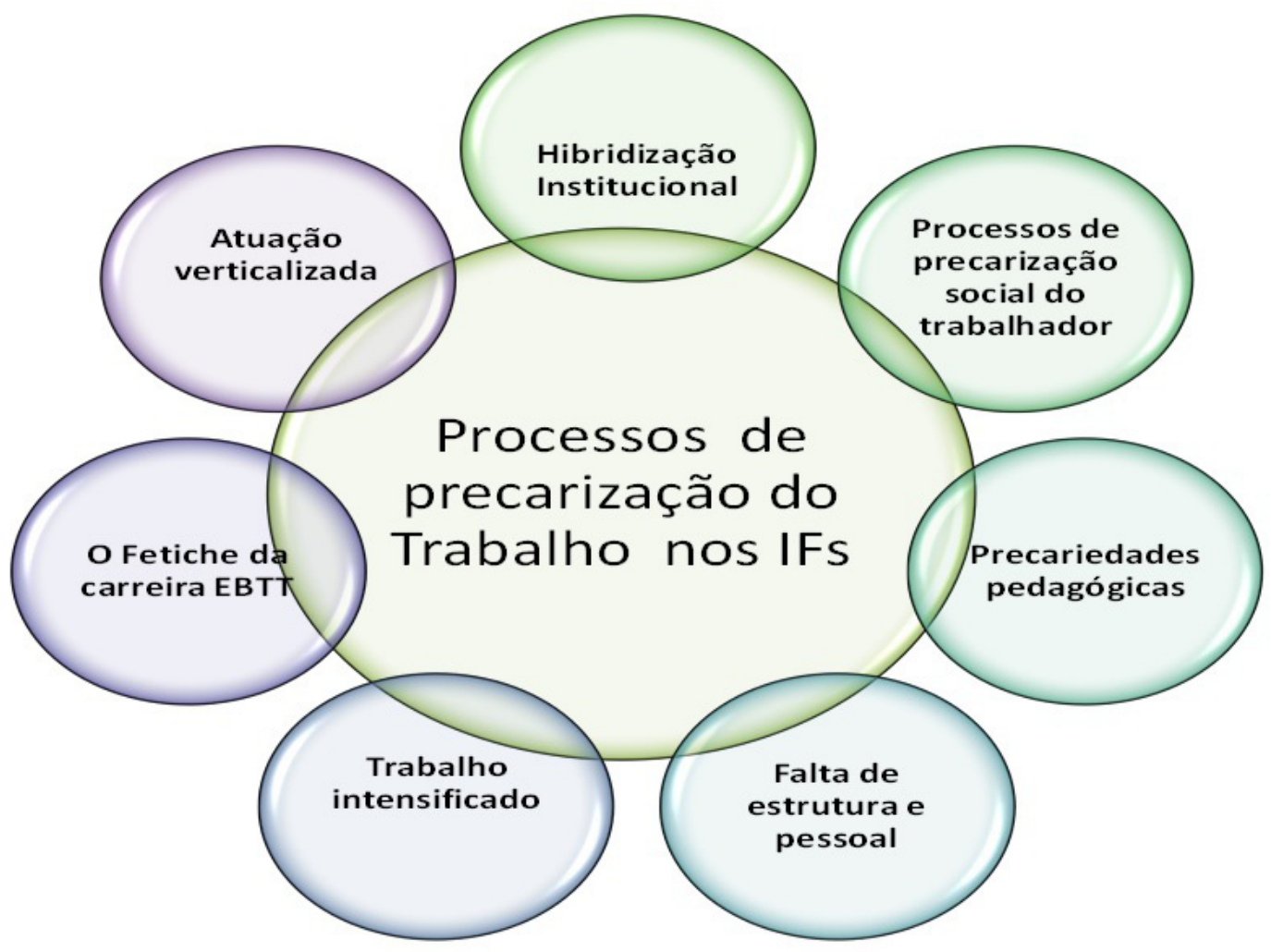

Fonte: Elaborada pelos autores.

A precarização do trabalho em Institutos Federais (IFs) está envolta em outros fenômenos com tentáculos que perpassam todo o processo formativo, a formação do educador e, também, a organização do trabalho. Assim, apontamos o fetiche da nova carreira nos IFs, a verticalização do trabalho, a intensificação entre os três principais processos da precarização do trabalho nesse espaço. 
Porém, não perdemos o horizonte de que a reestruturação da Rede de Escolas Técnicas Federais no Brasil, em 2008, expressa na segunda fase da política de expansão da Rede Federal de Educação Profissional, Científica e Tecnológica, construiu um novo formato de trabalho que, associado à hibridização institucional, leva à intensificação do trabalho docente nesse lócus. Nesse sentido, nas seções seguintes, discutiremos os elementos que evidenciam o processo de precarização do trabalho docente nos IFs, por meio da intensificação e dos processos organizacionais do trabalho.

\section{O fetiche da nova carreira nos IFs}

A reestruturação da carreira profissional na Rede, fundamentada nas Leis n.11.784/2008; 12.772/12 e 12.863/13, criou uma ocupação - professor EBTT - que é flexível e intensificada em sua gênese. Para entender como a carreira de magistério do ensino básico, técnico e tecnológico (EBTT) chegou a esse estágio de flexibilização, é preciso analisar sua construção histórica. A Rede Federal tem mais de cem anos de história, porém os planos de carreira só foram efetivados nos anos 1970. Assim, esses profissionais só tiveram quatro carreiras definidas a partir de 1974, como se pode analisar no quadro 1:

Quadro 1 - Carreiras dos professores da educação profissional federal no Brasil

\begin{tabular}{|c|c|c|c|}
\hline Ano & Plano de Carreira & Ano & Carreira \\
\hline \multirow[b]{2}{*}{1970} & \multirow{2}{*}{$\begin{array}{l}\text { Plano de Classificação de Cargos do Serviço Civil da União e } \\
\text { das Autarquias Federais - Grupo Magistério do Serviço Civil da } \\
\left.\text { União e das Autarquias Federais (Lei } n^{\circ} .5 .645 / 1970\right)\end{array}$} & 1974 & $\begin{array}{l}\text { Carreira Funcional do professor de ensino } 1^{\circ} \text { e } 2^{\circ} \\
\text { graus. }\end{array}$ \\
\hline & & 1981 & $\begin{array}{l}\text { Carreira do Magistério de } 1^{\circ} \text { e } 2^{\circ} \text { graus do Serviço } \\
\text { Público Civil, da União e das Autarquias Federais. }\end{array}$ \\
\hline \multirow[b]{2}{*}{1987} & \multirow{2}{*}{$\begin{array}{l}\text { Plano Único de Classificação e Retribuição de Cargos e } \\
\text { Empregos - PUCRCE (Lei nº 7.596/1987) }\end{array}$} & 1987 & \multirow{2}{*}{ Carreira do Magistério de $1^{\circ}$ e $2^{\circ}$ graus } \\
\hline & & 2006 & \\
\hline \multirow[b]{2}{*}{2008} & \multirow{2}{*}{$\begin{array}{l}\text { Plano de Carreira e Cargos de Magistério do Ensino Básico, } \\
\text { Técnico e Tecnológico (Lei nº 11.784/2008) }\end{array}$} & 2008 & \multirow{2}{*}{$\begin{array}{l}\text { Carreira do Magistério do Ensino Básico, Técnico e } \\
\text { Tecnológico. }\end{array}$} \\
\hline & & 2012 & \\
\hline
\end{tabular}

Fonte: (DOMINIK, 2017, p. 17).

A atual carreira de magistério do Ensino Básico, Técnico e Tecnológico (EBTT) é recente tendo em vista que foi criada pela Lei n. 11.784, de 22 de setembro de 2008 (BRASIL, 2008a). Em dezembro do mesmo ano, a criação dos Institutos Federais, a Carreira do Magistério do Ensino Básico, Técnico e Tecnológico trouxe diversas mudanças e rupturas. Prevendo como atribuições o ensino, a pesquisa e a extensão do ensino médio integrado, e pós-graduação, a possibilidade de atuação no exercício de direção, assessoramento, chefia, coordenação e assistência na própria instituição (BRASIL, 2008b). Porém, o governo mudou a regra em dezembro de 2012, com a edição da Lei n. 12.772/2012, criando duas carreiras e uma regra para quem havia entrado antes e para quem entrasse depois de $1^{\circ}$ março de 2013.

Em 2013, com a edição da Lei n. 12.863 novamente se alterou a carreira e definiu as classes da carreira EBTT como: D I ${ }^{6}$ (com os dois níveis) classe inicial independente da

\footnotetext{
6- 0 professor do magistério de EBTT só tem direito à aceleração da promoção depois de decorrida a avaliação de estágio probatório, que
} ocorrerá após três anos de efetivo exercício de suas funções no cargo. 
formação do docente; e as classes D II (com dois níveis), D III ( com quatro níveis), D IV (com quatro níveis) e Titular (BRASIL, 2013a). Em comparação com as carreiras anteriores, foi suprimida a classe D-V. Entretanto, a classe D-IV, que tinha apenas um nível, passou a ter quatro níveis. Assim, a diminuição de níveis uniformizou, mas não unificou a Carreira de Magistério Superior e a Carreira de Magistério do Ensino Básico, Técnico e Tecnológico. Parece haver uma uniformização da estrutura das Carreiras do Magistério Superior ${ }^{7}$ e de EBTT, com a diminuição de níveis, porém, não existe uma unificação das carreiras.

No campo da mediação e contradição, o governo estabeleceu o Reconhecimento de Saberes e Competências (RSC) ${ }^{8}$ como característica apenas da carreira de professor de EBTT. O RSC é uma espécie de prêmio de consolação para os professores de EBTT. Em breves linhas, sem ter a titulação exigida para ascender à classe, o professor faz jus à Retribuição por Titulação (RT) ao comprovar atividades de ensino, pesquisa e extensão, mas, por outro lado, só faz progressão entre as classes com o tempo de trabalho, pois não tem ainda o título exigido para tal fim.

0 elemento novo da carreira de EBTT é a atuação verticalizada. Essa pressupõe que a instituição deve desenvolver níveis, etapas e modalidades diferentes, e, com isto, o professor deve também atuar em níveis, etapas e modalidades distintas. Nesse sentido, constata-se, conforme Costa (2016), que a carreira EBTT sofreu os maiores impactos, pois esses docentes atuam em todos os níveis e modalidades de ensino da instituição, trazendo riscos para o ensino, para a relação força de trabalho/alunos e carga horária.

Assim, a verticalização é uma atualização da concepção da educação como bem de consumo, à medida que compreende que uma instituição que pode desenvolver ensino em todos os níveis e modalidades. Esse fato leva o professor de EBTT a trabalhar de maneira vertical em diversos níveis de ensino, o que intensifica o trabalho docente e precariza o fazer profissional, como se discutirá na próxima subseção.

\section{A verticalização do trabalho docente nos IFs}

As funções do professor de EBTT estão definidas na lei de criação dos IFs (BRASIL, 2008a), no artigo $6^{\circ}$, ao estabelecer que os IFs devem ofertar educação profissional e tecnológica, em todos os seus níveis e modalidades. Com ênfase no desenvolvimento socioeconômico local, regional e nacional; desenvolver a educação profissional e

7- Carreira de Magistério Superior, composta pelos cargos, de nível superior de que trata a Lei n 7.596, de 10 de abril de 1987, que trata dos cargos dos professores que atuam em Universidades Federais, que possuem nomenclatura e classes diferentes da carreira EBTT.

$\mathbf{8}$ - A resolução CPRSC/SETEC/MEC n. 1, de 20 de fevereiro de 2014 (BRASIL, 2014), estabeleceu as diretrizes e os procedimentos para a concessão de Reconhecimento de Saberes e Competências aos docentes da Carreira de Magistério do Ensino Básico, Técnico e Tecnológico, por meio de processo avaliativo especial. É processo de seleção pelo qual são reconhecidos os conhecimentos e habilidades desenvolvidos a partir da experiência individual e profissional, bem como no exercício das atividades realizadas no âmbito acadêmico, para efeito do disposto no artigo 18 da Lei $n^{0}$ 12.772, de 2012. São concedidos três tipos de Reconhecimento de Saberes e Competências (RSC); a) RSC I - Reconhecimento das experiências individuais e profissionais, relativas às atividades de docência e/ou orientação, e/ou produção de ambientes de aprendizagem, e/ou gestão, e/ou formação complementar, neste caso fazem jus os docentes que possuem apenas o título de graduação; b) RSC II - Reconhecimento da participação em programas e projetos institucionais, participação em projetos de pesquisa, extensão e/ou inovação atribuída a docentes com especialização lato sensu e; c) RSC III - Reconhecimento de destacada referência do professor, em programas e projetos institucionais e/ou de pesquisa, extensão e/ou inovação, na área de atuação fazem jus os docentes com título de mestrado. Neste caso, docentes com graduação passam a perceber vencimentos correspondentes ao especialista (no caso da RSC I), com especialização equiparam seus vencimentos aos detentores do título de mestre (RSC II) e aqueles que possuem mestrado percebem os vencimentos daqueles que possuem o título de doutor (RSC III). 
tecnológica; promover a integração e a verticalização da educação básica à educação profissional e educação superior; otimizar a infraestrutura física, os quadros de pessoal e os recursos de gestão (BRASIL, 2008a).

A verticalização ${ }^{9}$, embora esteja citada apenas uma vez na lei que cria os Institutos Federais, passa a ser entendida como inovação pedagógica capaz de gerar novos processos de ensino e aprendizagem. Segundo o discurso oficial, "a transversalidade e a verticalização constituem aspectos que contribuem para a singularidade do desenho curricular nas ofertas educativas dessas instituições" (PACHECO, 2011, p. 20).

Por conseguinte, verticalizar pressupõe que a instituição ofereça o ensino em todos os níveis e modalidades, ou seja, ministre educação profissional técnica de nível médio, cursos em nível de educação superior de tecnologia, licenciaturas, bacharelado e engenharia, e, ainda, cursos de pós-graduação lato e stricto sensu.

Esse processo é ao mesmo tempo uma estratégia administrativo-gerencial e uma estratégia pedagógica (FLORO, 2014). No que se refere à estratégia administrativogerencial, está pautada no aumento da produtividade do professor e da própria instituição. Dessa feita, o ponto de partida da criação dos IFs foi o aproveitamento da infraestrutura física das escolas profissionais da Rede Federal, por meio da cooptação dos CEFETs e escolas técnicas federais para adesão às chamadas públicas n. 1 e n. 2 (BRASIL, 2007a; 2007b) que se materializou na Lei n. 11.892/2008, levando essas instituições a abdicar da sua antiga configuração jurídica e pedagógica em prol da nova institucionalidade.

Segundo Righes et al. (2014), os fundamentos da verticalização alcançam estágios distintos de formação que são integrados e comunicativos, envolvendo o trabalho, o conhecimento universalizado e a inovação tecnológica. Essa suposta originalidade da verticalização como processo administrativo-gerencial estaria no cerne da reestruturação da Rede e da institucionalidade.

Porém, a oferta educativa para diversos níveis, etapas e modalidades numa mesma instituição pauta-se pela intenção de aproveitamento da estrutura física e humana dessas instituições na tentativa de fazer mais com menos. Por isso, a verticalização não se limita somente às propostas formativas ou à estruturação dos cursos: "vai muito além abraçando os mais variados aspectos da dinâmica institucional, principalmente na precarização das condições de trabalho" (BERTUANI, 2013, p. 05).

A precarização ocorre, nesse sentido, porque essa otimização do quadro de pessoal provoca uma atividade docente flexível e intensificada em sua gênese. Primeiro porque se acentua o trabalho docente ao submeter o professor a trabalhar com níveis e etapas distintas. Por outro lado, o mesmo professor exerce funções diferentes na carreira, pois executa a função de magistério de ensino superior, concomitante com as atribuições da carreira de professor de educação básica. Esse processo provoca a intensificação do trabalho docente, como discutiremos na subseção a seguir.

\footnotetext{
9- No mundo empresarial, a verticalização é a estratégia que prevê que a empresa produzirá internamente tudo o que puder, prática comum no início do Século XX, quando as grandes empresas praticamente produziam tudo o que usavam nos produtos. Nos IFs, ela está definida como oferta de cursos da mesma base científica ou tecnológica que ocorrem do ensino médio ao superior e é, também, atuação do trabalho docente em níveis e segmentos diferentes.
} 


\section{A intensificação do trabalho docente nos IFs}

Apoiados na descrição marxiana de gasto aumentado de trabalho em um mesmo espaço de tempo, compreendemos, também, a intensificação como processo ou organização que exige "mais trabalho e resultados no mesmo espaço de tempo, o que significa aumentar a exploração do trabalho" (DAL ROSSO, 2008, p. 45) e provocar a precarização social do trabalho.

Em síntese, o processo de intensificação da carga laboral, de diminuição da porosidade, do alongamento da jornada ou da produtividade por mecanismos organizacionais são formas de exploração da força de trabalho.

Compreendemos, assim, a intensificação como gasto aumentado de trabalho em um mesmo espaço de tempo que provoca densidade laboral. No IF estudado, essa intensidade processa e/ou processou pela (o):

a) Reestruturação da carreira e da Rede que criou a verticalização como modelo de atuação docente e a invenção de uma instituição híbrida como modelo de instituição escolar.

b) Aumento da densidade laboral, uma vez que o professor atua/atuava em segmentos e níveis de ensino diferentes no mesmo espaço de tempo.

c) A flexibilização da hora/aula que provoca/provocou um aumento disfarçado da carga horária e exige mais dispêndio da força de trabalho e do tempo do professor.

A intenção é organizar o trabalho para que as instituições se tornem mais eficientes, com o objetivo de garantir maior disciplina do trabalho e maior eficiência, concretizandose na intensificação e precarização do trabalho dos professores e dos técnicos. A verticalização, dessa forma, produz esse agigantamento do trabalho docente uma vez que ele deve atuar, por prerrogativa da carreira, em niveis e modalidades diferentes.

A verticalização passa ser vista como eficiência do trabalho, como característica positiva da Rede, como diferencial em relação às universidades públicas. Em parte, não discordamos de tal assertiva, porém verifica-se que ela, também, escamoteia outros processos que deixam de ser percebidos no interior do trabalho. Dentre eles, podemos enumerar: a atuação de bacharéis na educação básica, sem a devida preparação pedagógica; o aumento do trabalho, visto que são níveis diferenciados; a ausência de projetos educativos realmente integradores; a desmobilização da classe e a falta de unidade do projeto formativo.

Em síntese, o trabalho polivalente executado pelo professor nos IFs exige, desse professor, habilidades novas e constantes para dar conta da tarefa de ensino para públicos diferentes, no mesmo intervalo de tempo, nos institutos federais.

\section{Conclusão}

Em síntese é preciso considerar seis questões acerca da precarização do trabalho nos Institutos Federais: 
I. Precário é um termo político. Significando trabalho inseguro, incerto, difícil e delicado. Refere-se às condições de vida e de trabalho sem ou com poucas garantias e/ou com formas de organização que procuram extrair mais trabalho do trabalhador.

II. 0 trabalho precário refere-se a todas as formas possíveis de exploração flexível do trabalho seja ele legal, ilegal, efetivo ou temporário. É o trabalho feito sobre velhas e/ ou novas condições organizativas que procuram explorar um novo quantum no trabalho para além do estabelecido na gênese das profissões.

III. A precariedade é uma terminologia usada como uma descrição combativa, de resistência, para enfatizar os momentos subjetivos da precarização.

IV. A precarização é um processo caleidoscópico. Refere-se à flexibilização a partir de baixo, à exploração constante do novo quantum do trabalho sem a alteração de seu estatuto. Em outra face, apresenta-se no ataque constante aos direitos trabalhistas, à diminuição de suas garantias e ao amparo social do trabalho. Em outro prisma, mostra os reflexos subjetivos de sofrimento, do adoecimento provocado pelas transformações constantes impostas à organização do trabalho.

V. Precarização do trabalho significa uma transformação do emprego garantido e permanente para empregos mal pagos, inseguros, subempregos, cada vez mais flexíveis. Observa-se, ainda, uma tendência à reformulação das carreiras públicas e a implantação de tecnologias para tornar o mesmo trabalho mais produtivo sem pagamento desta nova produtividade. Em escala histórica e global, no entanto, o trabalho precário não é excepcional, é uma realidade concreta que se estabelece em todos os campos de trabalho seja ele o setor público ou privado.

VI. A precarização como termo político, insurgente, termo de luta e combate, constitui-se como uma potente categoria analítica para o processo de exploração da classe trabalhadora e sugere uma nova qualidade social do trabalho. Trabalho e vida social, produção e reprodução não podem mais ser separados, o que leva a uma definição mais abrangente de precarização: a incerteza de todas as circunstâncias nas condições materiais e imateriais da vida do trabalho vivo sob o capitalismo contemporâneo, sob a tentativa de construção de um novo regime de profissões para a nova sociabilidade.

Precarização simboliza, assim, um campo contestado: um campo em que a tentativa de iniciar um novo ciclo de exploração também atende desejos e comportamentos subjetivos, que expressam a recusa do velho regime fordista do trabalho e a busca de outro mais flexível que ameaça a vida.

As formas de precarização do trabalho docente nos IFs têm-se mostrado envoltas: em questões salariais; em condições materiais de trabalho; na intensificação do trabalho; na diminuição da jornada, com adensamento das atividades; na informatização das atividades docentes e seu controle remoto ${ }^{10}$; e no aumento do quantum do trabalho pelo aumento da grandeza extensiva e subjetiva da jornada.

Esse fenômeno no campo educacional está ligado à imposição das reformas educativas que são frutos da agenda global por educação e da política neoliberal. Seus efeitos são visíveis na colonização do mundo da escola pelo mundo do capital, transformando o que

10- Por meio da implantação dos sistemas de gestão do trabalho docente: diário eletrônico, pontos, sistemas de gestão dentre outros. 
a sociedade espera da escola, de suas formas de trabalho, da contratação e do regime de trabalho dos docentes, da avaliação da performance dos alunos/ dos professores e do ensino.

Entendemos que a precarização do trabalho é o conjunto de profundas transformações societárias no mundo do trabalho provocadas pelos ajustes neoliberais e a financeirização do Capital, que tem na flexibilização das condições de trabalho, de salário, de emprego, das relações trabalhistas, no desmantelamento da representação classista sua condição de existência. Assim, o conceito de trabalho precário e sua materialização estão ligados aos processos de desmantelamento de todos os tipos de trabalho no contexto da globalização e do neoliberalismo. Referem-se às pressões e aos ajustes fiscais e trabalhistas que, nas últimas décadas, têm estado presentes nas instituições de educação pública.

$\mathrm{Na}$ realidade concreta do fazer pedagógico dos institutos federais, a precarização:

a) Reduz o tempo de descanso durante a jornada de trabalho, já que, para atuar em níveis distintos, o docente gasta tempo diferente para planejar cada aula, que exigirá densidade e profundidade intelectual diferenciada.

b) Encurtamento do tempo para a autocapacitação docente. Em outras palavras, é um professor que encontra pouco tempo para a leitura, pesquisa, extensão que possibilitariam aprofundamento e atualização do seu próprio conhecimento.

c) Reduz a qualidade do serviço, pois quanto mais o docente está envolvido com o seu fazer pedagógico (com a produção), de pouco tempo dispõe para pensar o objeto de ensino e torná-lo, com as suas próprias faculdades, mais aprimorado. 0 trabalho perde qualidade, pois é realizado sem reflexão, sem planejamento, sem tempo/espaço para construí-lo na perspectiva da transformação.

d) Diversificação forçada da especialização e da responsabilidade docente para cobrir a falta de pessoal. Assim, são criadas estratégias gerenciais que possibilitam aumentar a carga horária docente sem necessariamente alterar os contratos de trabalho.

A precarização do trabalho docente, nesse caso, pode condicionar o educador a mecanizar/ automatizar suas práticas, alienando o ensinar, pois é obrigado a fazê-lo como exigência mercadológica do sistema capitalista passível de produzir conhecimentos descartáveis.

\section{Referências}

ALVES, Giovanni. Trabalho, subjetividade e capitalismo manipulatório - 0 novo metabolismo social do trabalho e a precarização do homem que trabalha. Revista da RET, Marília, v. 5, n. 8, p. 1-31, 2011. Disponível em: http://www.estudosdotrabalho.org/4_8\%20Artigo\%20ALVES.pdf. Acesso em: 03 nov. 2020.

ANTUNES, Ricardo; PRAUN, Luci. A sociedade dos adoecimentos no trabalho. Serviço Social \& Sociedade, São Paulo, n. 123, p. 407-427, set. 2015. Disponível em: http://www.scielo.br/scielo.php?script=sci_ arttext\&pid=S0101-66282015000300407\&lng=pt\&nrm=iso. Acesso em: 20 maio 2019.

BERTUANI, Adeylson Lichtenheld C. A verticalização do ensino nos IFET's na perspectiva da acumulação flexível de capitais. Sinasefe, Brasilia, DF, 13 jun. 2013. Disponível em: http://www.sinasefe.org.br/v3/ index.php?option=com_docman\&amp;task=cat_view\&amp;gid=243\&amp;|temid=57. Acesso em: 18 abr. 2017. 
BOSI, Antônio P. A precarização do trabalho docente nas instituições de ensino superior do Brasil nesses últimos 25 anos. Educação \& Sociedade, Campinas, v. 28, n. 101, p. 1503-1523, set./dez. 2007. Disponível em: http://www.scielo.br/pdf/es/v28n101/a1228101.pdf. Acesso em: 10 dez. 2018.

BRASIL. Chamada pública MEC/SETEC n. ${ }^{0}$ 001/2007. Chamada pública de propostas para apoio ao Plano de Expansão da Rede Federal de Educação Tecnológica - Fase Il. Brasília, DF: MEC, 2007a.

BRASIL. Chamada pública MEC/SETEC n. ${ }^{0}$ 002/2007. Chamada pública de propostas para apoio ao Plano de Expansão da Rede Federal de Educação Tecnológica - Fase Il. Brasília, DF: MEC, 2007b.

BRASIL. Lei n. 11.784, de 22 de setembro de 2008. Dispõe sobre a reestruturação do Plano Geral de Cargos do Poder Executivo - PGPE. Brasília, DF: Governo Federal, 2008b. Disponível em: http://www. planalto.gov.br/ccivil_03/_Ato2007-010/2008/Lei/L11784.htm. Acesso em: 20 ago. 2014.

BRASIL. Lei n. 11. 892, de 29 de dezembro de 2008. Institui a Rede Federal de Educação Profissional, Científica e Tecnológica, cria os Institutos Federais de Educação, Ciência e Tecnologia, e dá outras providências. Brasília, DF: Governo Federal, 2008a. Disponível em: http://www.planalto.gov.br/ccivil_03/_ ato2007-2010/2008/lei//11892.html. Acesso em: 29 set. 2014.

BRASIL. Lei n. 12.772, de 28 de dezembro de 2012. Dispõe sobre a estruturação do Plano de Carreiras e Cargos de Magistério Federal; sobre a Carreira do Magistério Superior, de que trata a Lei no 7.596, de 10 de abril de 1987 [...]. Brasília, DF: Governo Federal, 2012. Disponível em: http://www.planalto.gov.br/ ccivil_03/_ato2011-2014/2012/lei/L12772compilado.htm. Acesso em: 20 ago. 2015.

BRASIL. Lei $n^{0}$ 12.863, de 24 de setembro de 2013. Altera a Lei no 12.772, de 28 de dezembro de 2012, que dispõe sobre a estruturação do Plano de Carreiras e Cargos de Magistério Federal. Brasília, DF: Governo Federal, 2013a. Disponível em: http://www.planalto.gov.br/ccivil_03/_Ato2011-2014/2013/Lei/ L12863.htm. Acesso em: 20 ago. 2015.

CERÓN, Manuel Sánchez; CRUZ, Francisca María del Sagrario Corte. La precarización del trabajo de los maestros de educación básica en América Latina. Revista Latinoamericana de Estudios Educativos, Mérida, v. 42, n. 1, p. 25-54, jan./mar.2012. Disponível em:https://www.redalyc.org/pdf/270/27023323003. pdf. Acesso em: 03 nov. 2020.

COSTA, Elen de Fátima Lago Barros. Trabalho e carreira docente nos institutos federais de educação, ciência e tecnologia. 2016. 265 p. Tese (Doutorado em Educação). - Universidade Federal de São Carlos, São Carlos, 2016.

DAL ROSSO, Sadi. Mais trabalho!: A intensificação do labor na sociedade contemporânea. São Paulo: Boitempo, 2008.

DAL ROSSO, Sadi; CARDOSO; Ana Cláudia Moreira. Intensidade do trabalho: questões conceituais e metodológicas. Revista Sociedade e Estado, Brasília, DF, v. 30, n. 3, p. 631-650, set./dez. 2015. Disponível em: http://www.scielo.br/scielo.php?script=sci_arttext\&pid=S0102-69922015000300631. Acesso em: 09 maio 2017. 
DOMINIK, Érik. A carreira docente EBTT: aspectos específicos e legislação. Bambuí: Érik Campos Dominik, 2017.

DRUCK, Graça. Trabalho, precarização e resistências: novos e velhos desafios? Caderno CRH, Salvador, v. 24, n. 01, p. 37-57, 2011. Disponível em: http://dx.doi.org/10.1590/S0103-49792011000400004. Acesso em: 10 jan. 2016.

FLORO, Elisângela Ferreira. 0 trabalho docente e verticalização do ensino nos Institutos Federais. In: ENDIP: A didática e a prática de ensino nas relações entre escola, formação de professores e sociedade, 17. 2014, Fortaleza. Anais... Fortaleza: [s. n.], 2014. Disponível em: http://www.uece.br/endipe2014/ebooks/ livro3/INSTITUTOS\%20FEDERAIS.pdf. Acesso em: 18 abr. 2017.

GUERRA, Isabel Carvalho. Pesquisa qualitativa e análise de conteúdo: sentidos e formas de uso. Parede: Principia, 2014.

LIMA, Telma Cristiane S; MIOTO, Regina Celia T. Procedimentos metodológicos na construção do conhecimento científico: a pesquisa bibliográfica. Revista Katálise, Florianópolis, v. 10, n. esp., p. 37-45, 2007.

LOURENCETTI, G. C. Mudanças sociais e reformas educacionais: repercussões no trabalho docente. 2004. 161 p. Tese (Doutorado em Educação Escolar) - Faculdade de Ciências e Letras, Universidade Estadual Paulista Júlio de Mesquita Filho, Araraquara, 2004.

MARX, Karl. 0 Capital: crítica da economia política. Tradução de Reginaldo de Sant'Anna. 33. ed. Rio de Janeiro: Civilização Brasileira, 2014.

MOTA, Daniel Pestana. Direito, trabalho e saúde: uma equação possível? In: VIZZACCARO-AMARAL, André Luís; MOTA, Daniel Pestana; ALVES, Giovanni (org.). Trabalho e saúde: a precarização do trabalho e a saúde do trabalhador no Século XXI. São Paulo: LTr, 2011. p. 187-200.

MOURA, Carolina Baruel de. A precarização do trabalho docente nas escolas estaduais paulistas. 2013. 127 p. Dissertação (Mestrado em Educação) - Faculdade de Filosofia e Ciências, Universidade Estadual Paulista Júlio de Mesquita Filho, Marília, 2013.

NOZAKI, Hajime Takeuchi. Educação física e reordenamento no mundo do trabalho: mediações da regulamentação da profissão. 2004. 399 f. Tese (Doutorado em Educação) - Faculdade de Educação, Universidade Federal Fluminense, Niterói, 2004.

PACHECO, Eliezer. Institutos federais: uma revolução na educação profissional e tecnológica. São Paulo: Moderna, 2011.

PINA, José Augusto; STOTZ, Eduardo Navarro. Intensificação do trabalho e saúde do trabalhador: uma abordagem teórica. Revista Brasileira de Saúde 0cupacional, São Paulo, v. 39, n. 130, p. 150-160, 2014.

RIGHES, Antonio Carlos Minussi et al. A verticalização do trabalho docente nos Institutos Federais de Educação, ciências e tecnologia: um processo de formação continua. In: CONGRESO INTERNACIONAL 
NUEVAS TENDENCIAS EN LA FORMAÇIÓN PERMANENTE DEL PROFESSORAD0, 4., 2014, Buenos Aires. Anais... Buenos Aires: [s. n.], 2014. Disponível em: http://educalab.es/-/iv-congreso-internacional-nuevastendencias-en-la-formacion-permanente-del-profesorado. Acesso em: 18 abr. 2017.

SANTOS, Paulo Roberto F. A intensificação da exploração da força de trabalho com a produção flexível: elementos para 0 debate. 0 social em Questão, Rio de janeiro, v. 16, n. 25/26, p. 137-156, 2011. Disponível em: http://osocialemquestao.ser.puc-rio.br/media/8_OSQ_25_26_Santos.pdf. Acesso em: 03 nov. 2020.

VARGAS, Francisco Beckenkamp. Trabalho, emprego, precariedade: dimensões conceituais em debate. Caderno CRH, Salvador, v. 29, n. 77, p. 313-331, maio/ago. 2016.

VIZZACCARO-AMARAL, André Luís. Da polissemia conceptual à crise categorial do desemprego: novas formas de estranhamento no capitalismo do século XXI. In: VIZZACCARO-AMARAL, André Luís; MOTA, Daniel Pestana; ALVES, Giovanni (org.). Trabalho e saúde: a precarização do trabalho e a saúde do trabalhador no Século XXI. São Paulo: LTr, 2011. p. 56-83

Recebido em: 18.07.2019

Revisado em: 12.11.2019

Aprovado em: 18.02.2020

José Júlio César do Nascimento Araújo é doutor em educação pela Universidade Federal do Amazonas (UFAM), professor no Instituto Federal do Acre.

Arminda Rachel Botelho Mourão é doutora em educação pela Pontifícia Universidade Católica de São Paulo (PUCSP). Atualmente é professora titular da Universidade Federal do Amazonas. 